\title{
Philosophical Attitude in Teachers: myth or
}

\section{reality?}

\author{
Andrew Philominraj ${ }^{1}$, Enrique Espinoza ${ }^{2}$, Nicol Quinteros ${ }^{1}$ \\ ${ }^{1}$ Department of Languages, Faculty of Education, Universidad Católica del Maule, Talca, Chile \\ andrew@ucm.cl; nicol23qr@gmail.com \\ ${ }^{2}$ Colegio Los Agustinos, Talca, Chile \\ eespinoza7751@gmail.com
}

\begin{abstract}
This article through a qualitative descriptive study gives account on the importance of the "philosophical attitude" in the teacher. The text presents the characteristics of the Chilean neoliberal educational system, the role of the teacher in new educational scenarios, and the definitions collected from Edmund Husserl's phenomenology of natural attitude and philosophical attitude. Unlike previous research, the results of the Likert questionnaire of this study show that teachers in the commune of Talca do consider the "philosophical attitude" to be fundamental in their pedagogical management.
\end{abstract}

Keywords- Attitude, Education, Formation, Philosophy, Professor.

\section{INTRODUCTION}

The educational communities are a powerful reflection of what a society is. The educational institution in Chile is in the focus of the social gaze today, high demands are being made to the teams of educators, in the sense of mobilizing education from a neoliberal system or educational market towards an Inclusive School that can offer "quality education".

In this line of opening educational spaces, which invites us to incorporate inclusion strategies into institutional projects, we think that the most successful teacher will be the one who has managed to incorporate into his or her imprint of professional traininga new point of view and an attitude of non-acceptance of the "natural", of the nonacceptance of everyday education. A successful teacher is the one who is critical, has a creative vision and a permanent search for the truth.Accompanied by his or her students, he or she generates research knowledge in order to elaborate learning. In short, a teacher with a "Philosophical Attitude" in the classroom.

For some time now, we have appreciated that the educational system needs to stop planning in the implementation of a curriculum based on the delivery of information, with emphasis on the memory skills. Today, what is requiredis a teacher who is able to fine tune with the proposals of the various Institutional Educational Project (IEP), in terms of the profile of a person that is desired to achieve through educational processes, in its axiological characteristics, and of course in the development of competencies and skills for learning. Thus, in these terms it is expected that a teacher will do a better job and will have a better performance, capable of critically examining himself/herself and his/her pedagogical praxis, and of establishing a critical dialogue of reality with his/her students.

The present article taking into account all these issues explores the existence of philosophical attitude in the development of pedagogical practice in a group of teachers who work in high schools in the city of Talca.

\section{NEOLIBERAL SYSTEM OF EDUCATION}

The current educational system in Chile seems to be undergoing a process of increasing dehumanization in its task of training people, as it is often disconnected from the reality of the students, offering information and contents that in practice are not useful for their needs. Consequently, education becomes a dogmatic and meaningless activity, closing off all possibility of thought, questioning, motivation and argumentation; therefore, it limits the attitude and the approach with the knowledge, desire and passion for knowledge of the student (Mariño, 2012). The application of basic neoliberal principles to education policies contemplated, among other things, the transfer of financing from the State to private education organizations and the implementation of market-type competition mechanisms among school institutions.

Towards the 1980s and on the eve of the so-called political transition to democracy, the results of the neoliberal experiment were in sight: pauperization of teaching, reduction of public spending on education, inequity in educational results, crisis in public education, and in broader terms, a generalized process of loss of faith and meaning on the part of educational actors (teachers, students, proxies) in the school system (Chávez, 2006). 
The 1990s brought a new reformist impulse, characterized by milestones such as the implementation of the Jornada Escolar Completa (Full School Day), a substantial increase in public spending on education, a broad curricular reform that affected the curricula of basic and secondary education, and a concern to establish in some way the improvement of the teaching career, generating incentives and improvement programs for teachers (Chávez, 2006).

As of 2014, the Chilean education system has drifted towards a process inspired by the principles of making education a true right and a social good, inspired by the so-called Law of Inclusion, which aims to put an end definitively to the prevailing market logic of the system and focus educational management on three pillars widely demanded by society: Quality, Equity and Free Education (Mineduc, 2017).

2.1 The role of the Teacher in new educative scenarios This scenario has also distorted the teaching action of the educator, by assigning in this format of market competition among institutions, a high relevance to the impact of the results achieved in the prestige of educational institutions, which seems to be generating teachers "coaches" of students to achieve adequate responses to learning measurement tests such as SIMCE and PSU.

Nowadays, The Chilean Government has regulated that no establishment that receives state contributions may have any type of selection of students, to these establishments (in general, this is the reality of subsidized private establishments), have been forbidden under penalty of severe sanctions to carry out any kind of discrimination against people who wish to join their educational project, stating that "the system will encourage educational establishments to be a meeting place between students of different socioeconomic, cultural, ethnic, gender, nationality or religion conditions (Mineduc, 2017), and mechanisms have been put in place to monitor compliance with these provisions, known as the Superintendence of Education. The concept of inclusiveness is challenging to the very profession of being teachers, it means opening the doors of conscience to a new way of "doing education", given that it must be opened to a much wider and diverse heterogeneity, diversity as a concept is very close to that of inclusion and in this scenario it could be inappropriate and ineffective to try to approach to a teacher management only from a "natural attitude". According to research, such as the one carried out by the FundaciónArauco et al., (2003), teachers are not prepared to work with diversity, they are unaware of the difficulties that students may present, and they feel that they have few technical tools to fulfil their tasks. In addition, they do not always have the human resources, in terms of specialists, to support and train their pedagogical work (Blanco, 2008).

A substantive requirement is the demand that arises for new teacher competencies and capacities in the context of inclusive education for teachertraining institutions; in this regard, it is necessary to train a professional to lead educational actions related to diversity from inclusion. The teacher should not only concentrate on the development of technical tools that allow him/her to eliminate the barriers of access and participation of certain students in education, but also to critically analyze the systems of inclusion/exclusion and the cultural representations and assumptions ascribed to the different markers of subjectivity, such as, for example, socioeconomic condition, forms of learning, nationality, ethnicity, gender, among others, which can have repercussions on actions of discrimination and social oppression (Infante, 2010).

In this context of inclusive education that attends to diversity, it is worth asking how the role of the teacher could be defined, not only from the point of view of technology, but rather from the teleology of being a teacher. The teacher must be an educated, virtuous person, who becomes a teacher when he or she teaches, but this happens when he or she teaches something else, not content, but rather that his or her highest teaching is not in what he or she says, but in what he or she does, and above all in what he or she is (Peña, 2004). The true teacher, the one of vocation and who is virtuous, understands that what he does must be related to the being, not to the having, having is proper to instruction, being is affected by culture, which impacts the ways of seeing and interpreting the world and our surrounding reality. One of the important capacities in the teacher is the ability to analyze and criticize the inclusive and exclusive elements that may be present in the environment of development of their task (Infante, 2010), we appreciate as relevant the need of the new teacher to develop a "philosophical attitude".

The teacher must progressively strive to develop an identity with the vision and mission of that institution, because it requires a teacher who is able to be involved in the definitions of Educational Project (PEI) of the establishment where he or she collaborates and who is also able to be impregnated with the main axiological questions present in the inspirations of his or her educational centre, in order to be an appropriate mediator between inclusive cross-sectional training and the type of student who aims to form a particular establishment. As Villalobos points out in his study on organizational philosophy in educational institutions, teachers are not adequately involved in the definitions of vision, mission, purposes, and educational strategies of educational 
centres, let alone in the definition of goals (Villalobos, 2013). We need a teacher with a critical attitude in his or her pedagogical task, a teacher who is capable of questioning the educational reality and his or her own reality, capable of being astonished at the different life experiences offered by his or her students, in order to engage in reflection that will allow him or her to find ways to better educate these young people (Infante, 2010).

2.2 Natural Attitude and Philosophical Attitude

Consequently, it seems that the greatest relevance to recover the philosophical attitude of the teacher is the understanding of this concept of attitude in its etymological derivation from the Italian attitudine, "aptitude", "posture", "attitude", probably of the same origin as aptitude. Joan Corominas' dictionary also refers to the fact that, despite the consensus on the previous meaning of the word, there is also another, that derives from actum, (act). As for the word aptitude, it seems to hide a greater wealth: derived from the Latin aptus, it shows the senses of "greatness", "wealth", "high", "noble". Therefore, firstly, the words attitude and aptitude are intimately linked, showing that one and the other are presupposed. Secondly, the sense of act manifests the attitude as an action, as a movement, the same that we could identify with a posture, that is, not with a spatial mobility, but with a spiritual action. Thirdly, we have that this act is full of aptitude, that is, it is an act that manifests richness (Paz Castillo, 2012).

Edmund Husserl (2012) divides this concept of attitude into two, pointing out that there is an attitude called "natural" and another that he mentions as "philosophical attitude". The "natural attitude" includes assuming all the typical daily acts that make up the existence of the human being and all that surrounds him in a per se way; that is, without any questioning, when explaining itself by itself, because they have always been there or, as Gil Claros expresses it well, "The natural attitude is the position that the subject assumes before the daily world, where life is expressed in its multiple manifestations such as business, house management, children's games, the city. At the same time it is a world of which we are fully aware of what we do as subjects. The natural attitude is something that belongs to those men of conscience, which helps to guide them and give meaning to the world in which they live(Gil, 2009). In the natural attitude man inherits a world with its previously constructed meanings and that can have different conceptions about what the universe is; different visions about what education is, different creeds of faith, doctrines, symbols, forms and rituals, because man is not born alone. He is born in a community that has its own history, his traditions, his ways and styles of doing things. Man maintains an idiosyncrasy that he assumes from the moment he is able to make use of his reason, he is born in a world with a certain sense of things, which as an individual he does not question; it is a world that maintains its own plot of meanings that serve to give meaning to things. Finally, man is heir to a world that is constituted and never questioned.

The "philosophical attitude" or as Husserl (2012) points out, the phenomenological attitude, understood as philosophical attitude, is to think the thinking, central object of his concerns. Consequently, the philosophical attitude would correspond to a type of phenomenological reflection: to think to itself, in the taking of a lead position of the thinking subject, that incorporates flows of experiences in the constitution of an image of the world. The philosophical attitude, in addition to thinking of itself, demands to know itself, to take care of itself and to govern itself, in order to develop a disposition or position of life from itself, reflected in a reflective and critical attitude in a subject with conscience of itself. In synthes is, we find ourselves before an acute subject in the observations of phenomena that develops a complex knowledge, in the different postures he assumes before what is observed in a pure consciousness. Provisionally we can say: The philosophical attitude is a taking of position before the phenomenon, assumed from a positional conscience in the subject (Gil, 2009).

The teacher in a state of "natural attitude" is installed in a prefabricated educational system where he himself was trained, he assumes it as his own and in general, although questions will always arise about certain aspects such as, for example, the question of the teaching vocation, the teacher who does not philosophize about his task will approach his delicate work with a look of "natural order", probably becoming a repeater of the curricula to its last letter, assuming without critical spirit the methodological and technical indications that are indicated to him from other levels. The teacher in "natural attitude" will also be a teacher who will transmit to his students a passive attitude to life and to the problems and contingencies he may confront. The "natural attitude" in the man resembles the form of the lived world where he finds himself within, as one body. But the so-called "natural attitude" of Husserl (2012), cannot be the characteristic of the teacher of the new educational times of the country, it is necessary to recover, to re-establish or if it does not exist, to install in the new generations of teachers the philosophical restlessness. The plans of teacher formation of the institutions of higher education must consider the strengthening of the knowledge in philosophy of the teacher, in order to guarantee the development of a "philosophical attitude" in its work of educating young people. 


\section{OBJECTIVES OF THIS STUDY}

3.1 GeneralObjective:

- To explore the existence of a philosophical attitude in the management of teachers in secondary schools in the city of Talca, as a support for their pedagogical practice.

3.2 Specific Objectives:

-To describe the quality of the educator's participation in the axiological definitions and inspiring principles of Vision and Mission in the educational work of the educational establishments of the city of Talca.

-To analyse the importance given by the teachers surveyed to the establishment of practices that develop a "philosophical attitude" in their students.

\section{METHODOLOGY AND DESIGN}

This empirical study explores in a group of teachers of the commune of Talca if the teacher, professional of education, at the same time that he strives to improve his work in the specific pedagogical practice of his subject, also worries to enrich his preparation by means of the acquisition of a philosophical culture, maintaining a role of effective transmitter of values and perspectives of life towards his students.

The teacher is described in his or her testimony of critical reflection on life, as a connector between specific contents and meta-cognitive elements, beyond the classroom, that make possible the development of the thinking of his or her students. The teacher requires a broad, long-term vision of the meaning of his or her action, a vision that can connect his or her daily efforts with the attainment of a better future for his or her students and for society (Amilburu, 2014).

This study seeks to explore this situation, inviting us to vindicate the philosophical formation of teachers, as a characteristic of the initial formation of the teacher, that allows us to broaden the teaching horizons, that can take the teacher out of the narrow school spaces, to question his or her own task, so that he or she can imagine other things, avoiding becoming stagnant because of routine, avoiding falling into "pedagogization" based on the control and absolute planning of the subject (Amilburu, 2014).

The work consists of carrying out a descriptive study that will then be empirically verified through a process of gathering information in the field, based on a Likert type Questionnaire, applied to a sample of secondary school teachers in the commune of Talca. Finally, a display of quantitative information will be carried out, which will be constructed on the basis of statistical data obtained from the application of the Likert Questionnaire, which will be analysed on the basis of the SPSS statistical protocol, and statistical tables and graphs will be drawn up with the information obtained for a better and more efficient analysis of the same.This data will be analysed using the SPSS statistical protocol through informative tables and statistical graphics. Likert Questionnaires answers of teachers will be held as classified information.

\section{DATA ANALYSIS}

According to the result of the Likert survey on "Philosophical Attitude", about the study of the relationship between teaching practice and the axiological philosophical approaches of educational action. Its analysis is carried out in four items, which are:

a) The relationship between teaching practice and the educational establishment context,

b) Question method,

c) Current education system; and

d) The teaching exercise around the philosophical attitude.

5.1 Relationship of the teaching exercise with the educational establishment context

In the context of teaching and educational establishment, three aspects were considered:

a) Teachers' knowledge of the mission and vision of the educational institution,

b) Knowledge of the value option prioritized by the establishment and

c) Knowledge of the profile of its students.

The results indicate that the educators are aware of the importance of knowing these three aspects of their educational establishment, from a scale of 1 to 5 , where 1 is completely in disagreement and 5 completely in agreement, the average of this exercise was 4.7 , which indicates that they are in full knowledge of the mission, vision, value option and profile of the student of the establishment. Besides the total of the survey, the recognition of the value option is the one that has the highest score with 4.9 , only one of a population of 14 teachers equivalent to $7 \%$ of the sample, choose option 4 , which is to agree very much and the remaining 93\% indicated to agree completely. The minimum score given by teachers for these three variables was 3 , which means that they agree. 


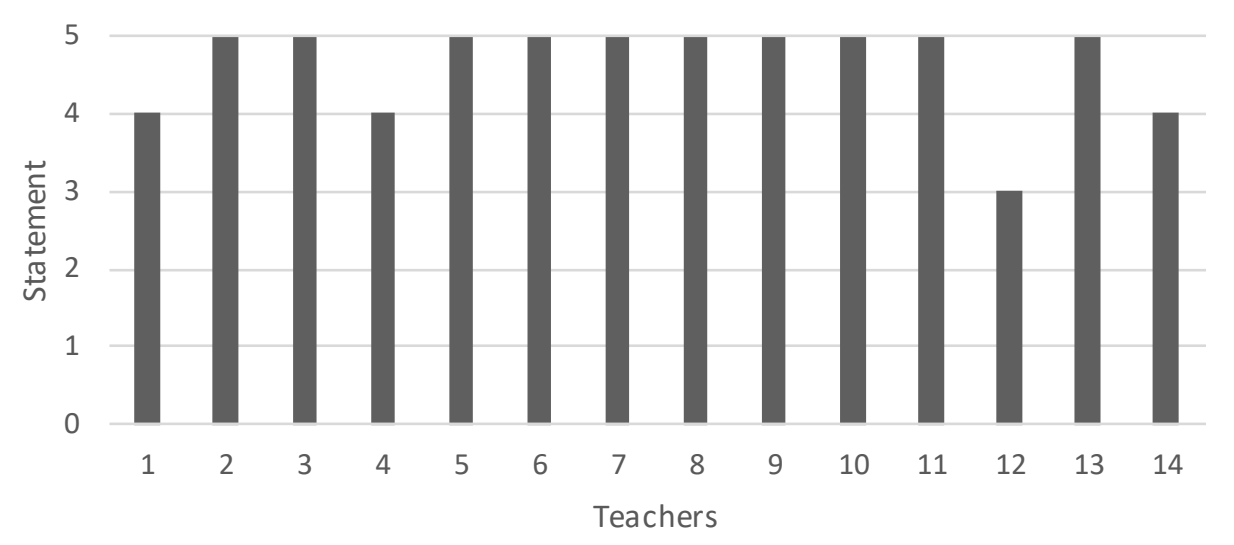

Fig.1: Knowledge of mission and vision of the educational establishment

Source: Prepared by authors

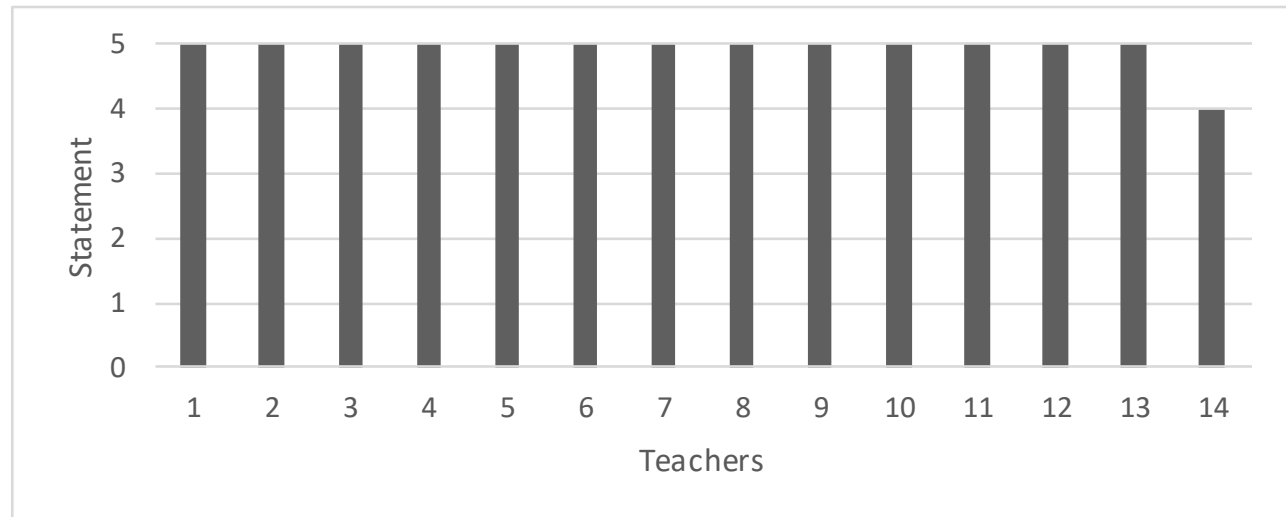

Fig.2: Knowledge of the establishment's prioritized set of values

Source: Prepared by authors

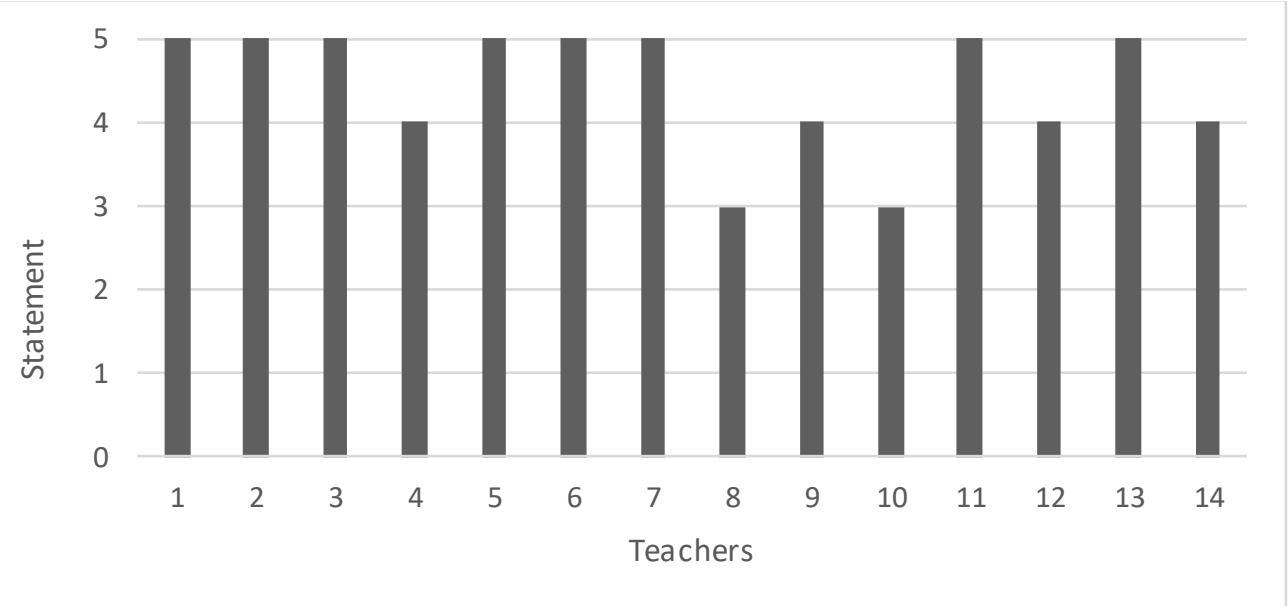

Fig.3: Knowledge of the students' profile of the establishment

Source: Prepared by authors

\subsection{Question Method}

This method helps students to go beyond the knowledge explained in class, to develop a critical and metacognitive attitude. As a result of the survey it is demonstrated that there is a high focus of teachers towards the motivation of their students, so that they can exercise a critical attitude and generate a greater knowledge than can be acquired by a class without this methodology, the average score to this question was 4.4 indicating through this, that they are very much in agreement in exercising this technique, 50\% of the teachers indicated to be completely in agreement, $43 \%$ indicated to be very much in agreement and the remaining $7 \%$ to be in agreement. 


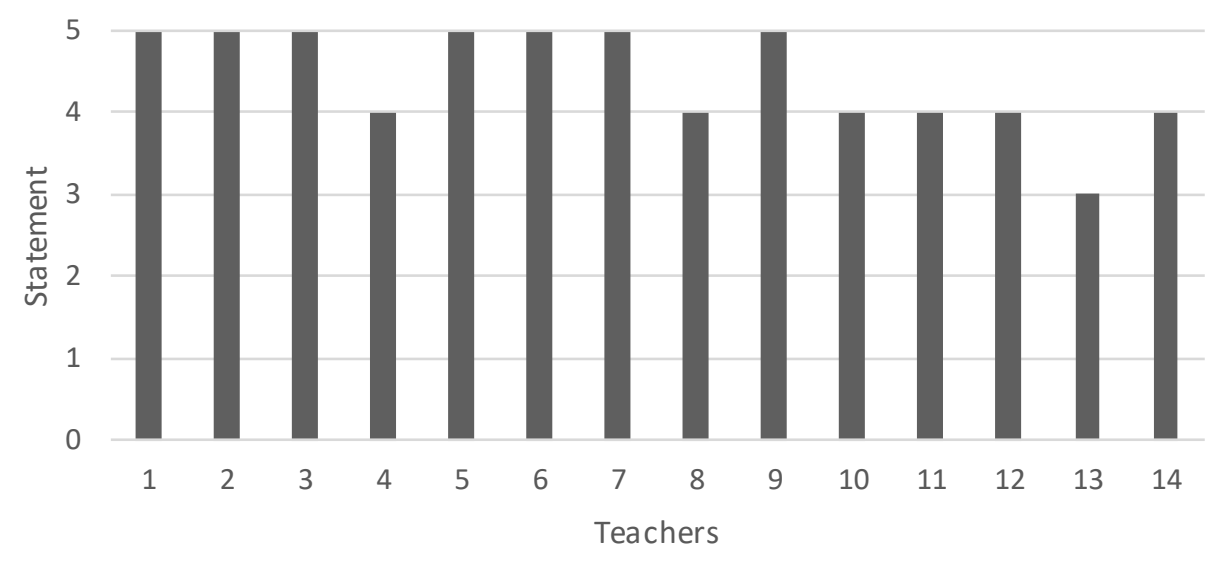

Source: Prepared by authors

Fig.4: Use of the question method.

5.3Current Educational System

The data exposed by the question addressed to whether the current education system gives time to internalize knowledge with its students and go beyond the contents evaluated by external measurements such as SIMCE and PSU are clear, the options completely agree, strongly agree and agree obtained $29 \%$ respectively and only $13 \%$ indicated disagreement with this statement.

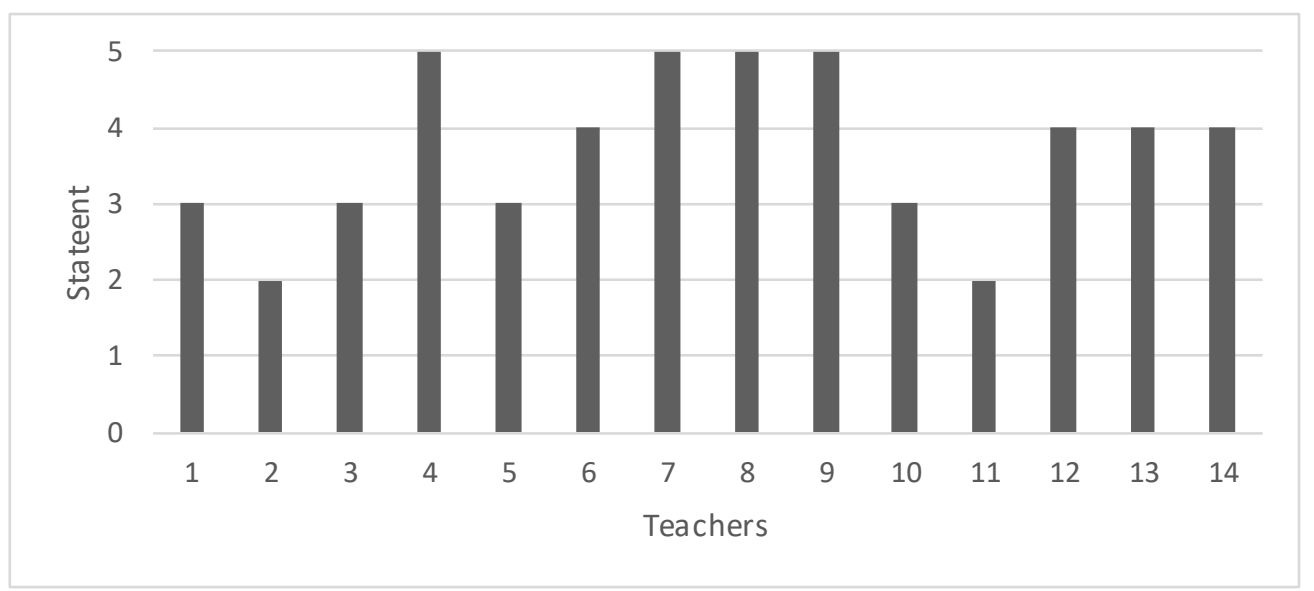

Source: Prepared by authors

Fig.5: Current educational system vs. external measurement

5.4 Teaching activity regarding philosophical attitude In the context of the teaching activity around philosophical attitude, three aspects were considered:

a) The importance of philosophical training in the performance of the educator,

b) The ability of the teacher to adopt a philosophical attitude, and c) The philosophical attitude as a generator of more inclusive teachers.

From a scale of 1 to 5, where 1 is completely in disagreement and 5 completely in agreement, the average of this exercise was 4.6, which indicates that this quality positively influences his performance as an educator. $64 \%$ agree completely with this statement, $29 \%$ agree very much and $7 \%$ agree. There were no teachers who disagreed on this item. 


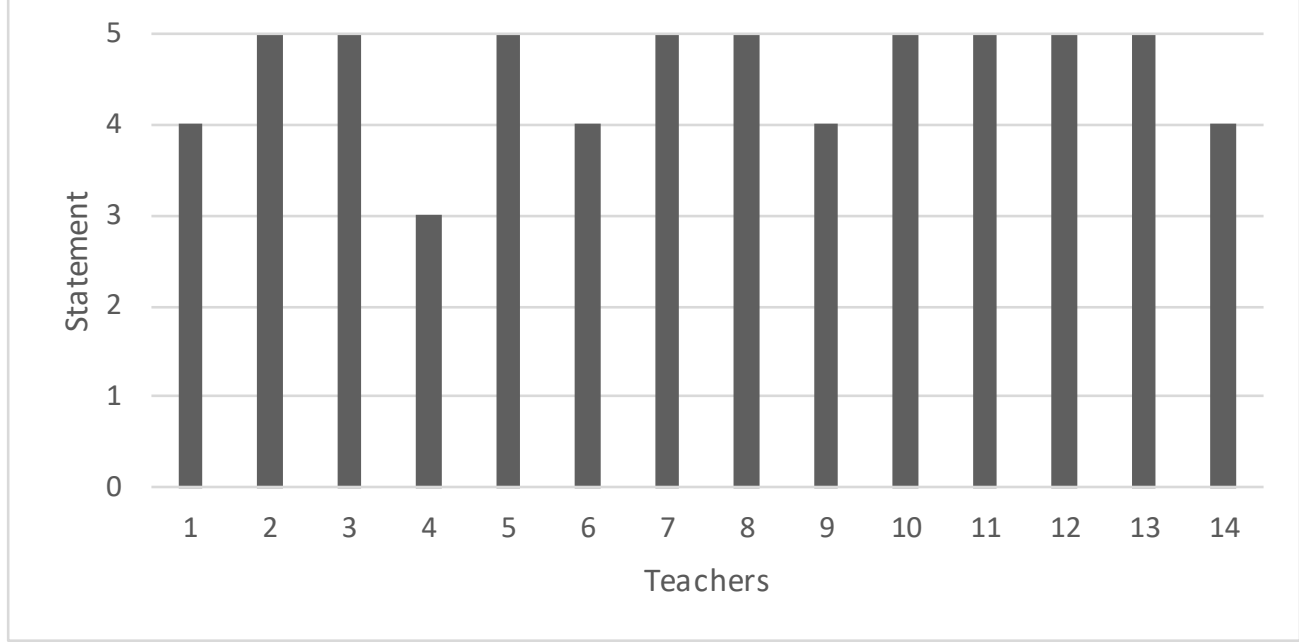

Fig.6: Importance of philosophical formation in the performance of the educator Source: Prepared by authors

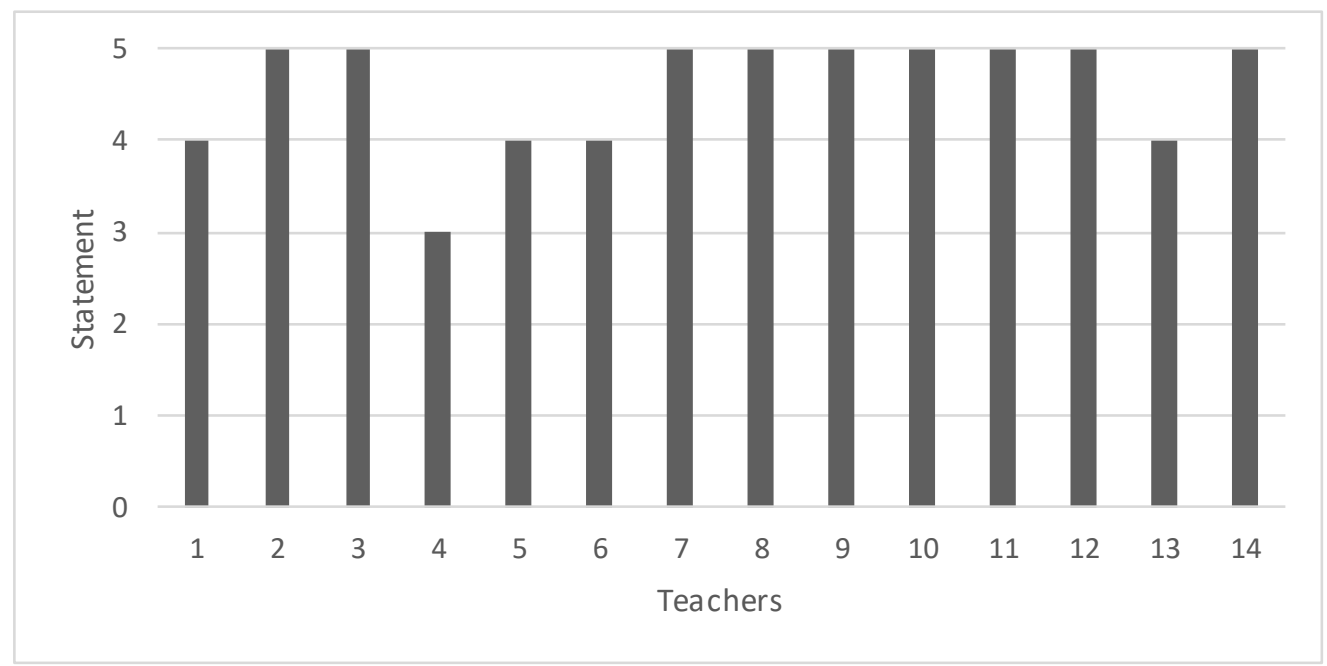

Fig.7: Capacity of adopting a philosophical attitude

Source: Prepared by authors

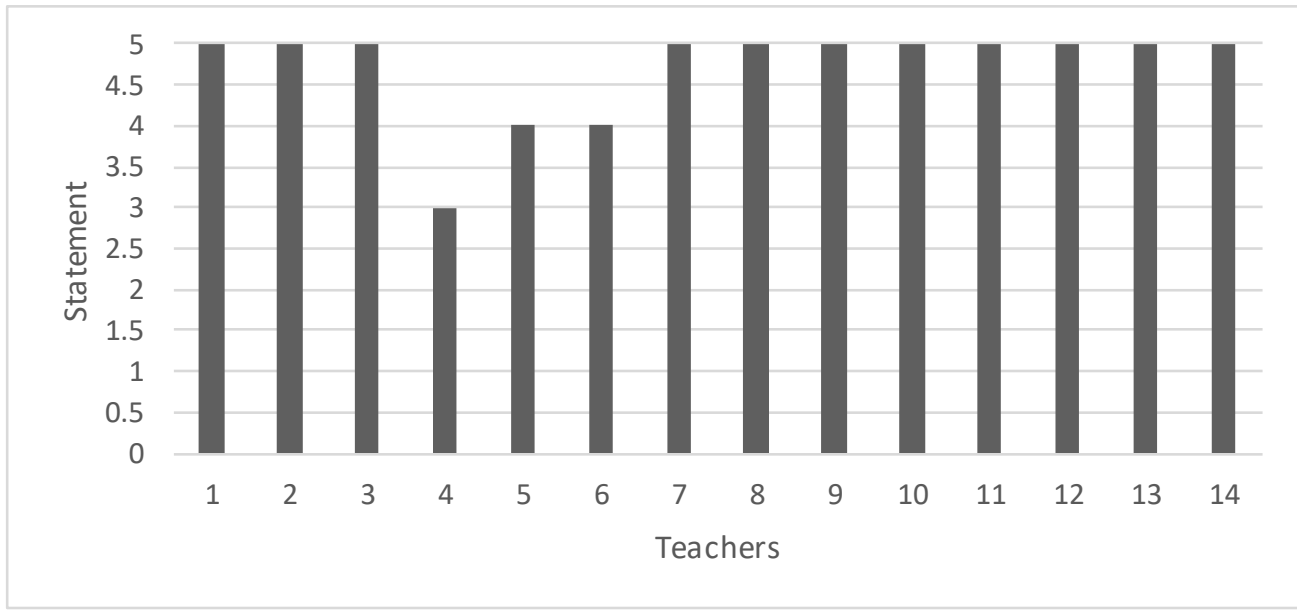

Fig.8: Philosophical Attitude vs. Inclusive Educator

Source: Prepared by authors 
5.5 Summary on Likert survey analys is "Philosophical Attitude"

According to the result of the Likert survey on "Philosophical Attitude", regarding the study of the relationship between teaching practice and the axiological philosophical approaches of educational action and the analysis of the four items mentioned above, we appreciate that there is a strong acceptance in each of the areas.

As a result of this, $75 \%$ of the items are placed in the interval of complete agreement / very much in agreement and the remaining $25 \%$ consider tobe between very agreement and agreement.

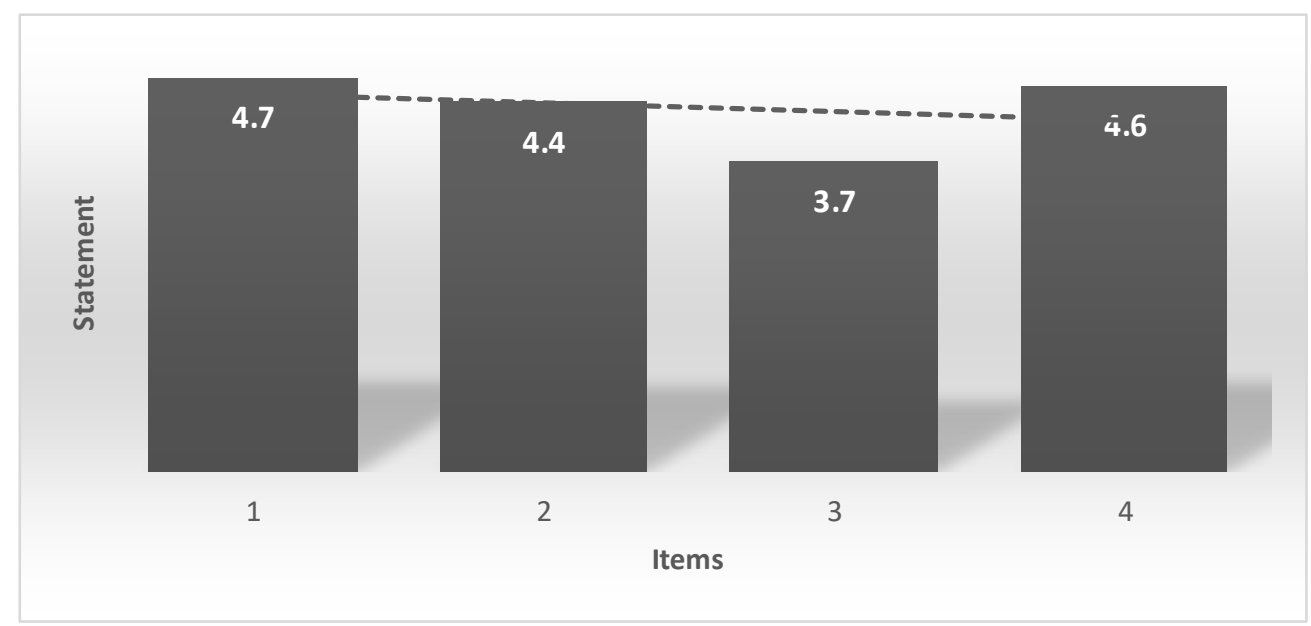

Fig.9: Summary of Likert survey in the relation to the four items

Source: Prepared by authors

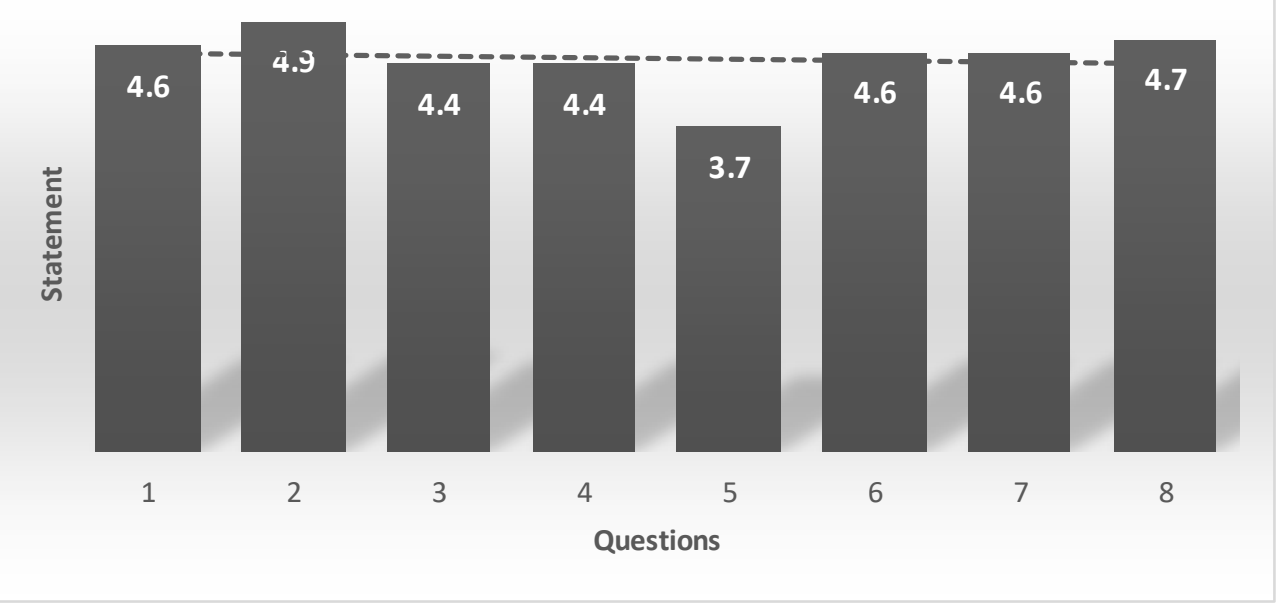

Source: Prepared by authors

Fig.10: Summary of Likert survey questions

On the other hand, analyzing the totality of the questions of the Likert survey "philosophical attitude" teachers consider to be completely in agreement or very much in agreement towards maintaining this attitude, which is very positive and has a direct impact on their teaching practice.Promoting to go beyond what is established and with this propitiating their own development, but what is even more important, is the formation of a generation of people with critical thinking that generates this philos ophical attitude.

\section{CONCLUSIONS}

From the data analysis, it can be stated that the teachers involved in this studywould not fulfil what Villalobos (2013) pointed out in his study on organizational philosophy in educational institutions. He stated that "teachers are not adequately involved in the definitions of vision, mission, purposes, and educational strategies of educational centres, much less in the definition of goals, so it generally occurs that teachers are unaware of the values declared in the establishment's management plans". Given the high percentage of teachers who indicated that they are fully aware of the purposes established in the Educational Project of the Institution in 
which they work, it is especially interesting to know that $93 \%$ of the teachers completely agree with the statements referring to the knowledge that teachers have about the mission and vision of the educational establishment, and also in terms of the option based on values prioritized by the establishment and the knowledge of the profile of its students.

At the same time, with regard to the statements about the importance of receiving philosophy training in your preparation as a teacher, $64 \%$ indicate complete agreement, $29 \%$ strongly agree, and $7 \%$ agree. This implies that $100 \%$ of the sample of teachers indicated that it is a fundamental contribution to their teaching work, and that they consider that assuming a "philosophical attitude" in the development of their pedagogical practice with the students allows them to develop this same attitude. Consequently, the teacher with a philosophical attitude generates more critical and reflective students, that is to say, people with more argumentative capacity.Hence, it could be concluded that the attitude of philosophizing in teachers is indeed a reality.

\section{REFERENCES}

[1] Amilburu, M. G. (2014). Filosofía y actitud filosófica: sus aportaciones a la educación. Revista Es pañola de Pedagogía, 72(258).

[2] Blanco, P. (2008). Construcción de significados que otorgan los profesores, de Educación Parvularia, Enseñanza Básica y de Enseñanza Media, al trabajo con la diversidad, en una escuela municipal de la comuna de la Región Metropolitana. Tesis Magister. Universidad de Chile.

[3] Chávez, R. C. (2006). El experimento educativo chileno 20 años después: una mirada crítica a los logros y falencias del sistema escolar. REICE: Revista Electrónica Iberoamericana sobre Calidad, Eficacia y Cambio en Educación. 4(1), 118-129.

[4] Fundación Arauco et al. (2003). Niños con necesidades Educativas Especiales, Cómo Enfrentar el Trabajo en el Aula. Ediciones Universidad Católica de Chile.

[5] Gil, M. (2009). Fenomenología y Actitud Filosófica. Universidad de Santiago de Cali.

[6] Husserl, E. (2012). La Idea de la Fenomenología. Edición 2012. Editorial Casa del Libro.

[7] Infante, M. (2010). Desafíos a la Formación Docente: La Inclusión Educativa. Pontificia Universidad Católica de Chile.

[8] Mariño, L. (2012) La Educación Filosófica como Experiencia y Posibilidad. Grupo de Investigación Filosofía, Sociedad y Educación. Universidad Pedagógica y Tecnológica de Colombia.
[9] Mineduc. https://www.mineduc.cl/

[10] Paz Castillo, E. (2012). La Actitud Filosófica. Revista Pueblo Continente, 23(1), 225-230. Universidad Privada Antenor Orrego.

[11] Peña, J. (2004). Entre la Actitud Culta del Alumno y la Virtud del Profesor. CEP CHILE Estudios Públicos. 292-315.

[12] Villalobos, J. (2013). Dialnet. Valores Organizacionales en la Filosofía de Gestión para Instituciones Educativas Bolivarianas. 35-48. 